\title{
Pediatric Nurses' Information and Applications Related To Ethical Codes
}

\author{
Ayse Sonay Turkmen ${ }^{1, *}$; Sevim Savaser ${ }^{1}$ \\ ${ }^{1}$ Nursing Deparment, Health School, Karamanoglu Mehmetbey University, Karaman, Turkey \\ *Corresponding author: Ayse Sonay Turkmen, Nursing Deparment, Health School, Karamanoglu Mehmetbey University, Karaman, Turkey. E-mail: asonaykurt@gmail.com
}

Received: November 30, 2013; Accepted: September 16, 2014

\begin{abstract}
Background: Ethics is defined as the entirety of moral principles that form the basis of individuals' behavior; it can also be defined as "moral theory" or "theoretical ethics".

Objectives: To determinate information and applications related to ethical codes of pediatric nurses.

Patients and Methods: Participants were nurses attending the Neonatal Intensive Care Unit Nursing Course and the Pediatric Nursing Course conducted in Istanbul between September 2011 and December 2012. A total of nurses attending the courses at the specified dates and who agreed to participate in the study were included in the analysis. Data were collected through a questionnaire that we developed in accordance with current literature on nursing ethics.

Results: 140 nurses participated in this study. Information and applications were related to ethical codes of nurses including four categories; autonomy, beneficence, nonmaleficence, justice. The principle of confidentiality/keeping secrets. Exactly 64.3\% of nurses reported having heard of nursing ethical codes. The best-known ethical code was the principle of justice. Furthermore, while the rates were generally low, some nurses engaged in unethical practices such as patient discrimination and prioritizing acquaintances.

Conclusions: We conclude that most nurses working in pediatric clinics act in compliance with ethical codes. We also found that the majority of nurses wanted to learn about ethical codes. For this reason, we recommended that nurses working in clinics and future nurses in training be informed of the appropriate ethical behavior and codes.

Keywords: Ethics; Nurse; Nursing
\end{abstract}

\section{Background}

Ethics is defined as the entirety of moral principles that form the basis of individuals' behavior; it can also be defined as "moral theory" or "theoretical ethics". In a narrower sense, it is the science of "correct" and "incorrect" behaviors. Ethics is the philosophy of investigating, through analytical thinking, the values at the basis of relations between humans and the characteristics of the moral terms of good/bad and right/wrong. This characteristic of analytical thinking distinguishes ethics from morals: ethics refers to a system of thought, while moral refers to the set of values that develop on their own with the rise and fall of different societies (1). Ethics guides how people view the relevance of each decision made in the field of health, and is separated into two subcategories: theoretical (philosophical) and applied. Theoretical ethics is concerned with the subject, meaning, and purpose behind philosophical ethics and examines its areas of responsibility. Applied ethics helps in deciding on what is right and wrong. By laying out the liabilities that each individual physician or health practitioner has towards him or herself and his or her patients, applied ethics teaches that physician the behavior that is in line with his or her own values. It assists in the decisions they must make, as well as their fulfillment with the profession; furthermore, it helps them avoid causing patients harm $(2,3)$. The Florence Nightingale Pledge, acknowledged as the first ethical code for the medical profession, included important guidance rules for nurses. Expressions such as "I will do all in my power to maintain and elevate the standard of my profession, and will hold in confidence all personal matters committed to my keeping and all family affairs coming to my knowledge in the practice of my calling. With loyalty will I endeavor to aid the physician in his work, and devote myself to the welfare of those committed to my care. I will abstain from whatever is deleterious and mischievous. I will not take or knowingly administer any harmful drug" helped to orient the purpose and function of the nursing profession when the pledge was first introduced, setting forth new professional values for nursing. Since then, nursing has become increasingly acknowledged as a profession with unique values and principles (4). However, the way in which the nursing profession changed over the years made it necessary to review and even amend these ethical codes. Thus, the American Nurses' Association (ANA, 1950) and the International Council of Nursing (ICN, 1953) reviewed the existing codes and established new versions. These "Nursing Ethics Codes" were presented with a new perspective on nursing, which demonstrated that nursing is an independent profession (5). With the

Copyright (C) 2015, Growth \& Development Research Center. This is an open-access article distributed under the terms of the Creative Commons Attribution-NonCommercial 4.0 International License (http://creativecommons.org/licenses/by-nc/4.0/) which permits copy and redistribute the material just in noncommercial usages, provided the original work is properly cited. 
scientific and technological developments in the field of health, ethical codes specific to nursing had to be developed to help resolve the ethical dilemmas encountered by nurses; since their development, these codes have become known as instruments describing the responsibilities and common values unique to the nursing profession. These values guide nurses in their activities and decision making, as well as how they disseminate health information to the general public. The ethical principles established by contemporary medical ethics fall into four categories, as follows: autonomy, beneficence, nonmaleficence, justice. Autonomy: This principle dictates that the individual is able to make decisions about his or her health according to his or her values, beliefs, and expectations without been exposed to any outside pressure. This principle is based on the principle of self-determination, and aims to protect human dignity. It asks nurses to respect each individual and their values, because everyone is entitled to make decisions on their own lives and expect health personnel to respect their decisions. The most significant reflection of the principle of autonomy in the field of health is informed consent. Individuals are only able to exercise these rights by having actual information about the situation at hand. Another principle forming the basis for informed consent is "truthfulness and honesty." The concept of informed consent, which is based on two fundamental ethics principles, places the responsibility on health professionals for informing patients and ensuring that patients understand what is happening to them during treatment; in addition, it entitles patients the right to refuse treatment in line with the provided information. This principle also refers to respecting the privacy of the patient during treatment and in any instance that the nurse is involved with the patient $(6,7)$. Beneficence: This principle is based on providing benefit to the patient. This principle provides guidance to nurses in prioritizing patient beneficence, doing good, and avoiding maleficence $(7,8)$. This principle is based on doing well. Maleficence: This principle is based on preventing maleficence. This means doing nothing that could harm someone else $(7,8)$. This principle consists of three hierarchically related elements: non-maleficence, preventing maleficence and eliminating maleficence. Justice: This principle refers to treating each individual fairly. It emphasizes the importance of being careful that resources at hand are shared, particularly when deciding on treatments $(4,6,7,9-12)$. Children are unable to defend their rights and require the advocacy of an adult, meaning that medical staff must also seek to protect the rights of the child (6). This important responsibility increases the possibility of pediatrics nurses encountering ethical and legal problems. Therefore, nurses must be able to overcome these problems and make correct decisions, which primarily requires them to know the basic concepts, laws, rules, and other information related to the issue, and to seek continual improvement of their own nursing skills (8). It is contemplated that number of peo- ple with enough information about these codes is quite low despite being a very important ethical codes especially in health-related fields. It has been found very few studies in the literature about ethical codes. One of the areas that most experienced of ethical issues is neonatal intensive care unit. After a literature review, we found no study describing the information and applications related to ethical codes of pediatric nurses.

\section{Objectives}

This study was done to determinate information and applications related to ethical codes of pediatric nurses.

\section{Patients and Methods}

Participants were nurses attending the Neonatal Intensive Care Unit Nursing Course and the Pediatric Nursing Course conducted in Istanbul between September 2011 and December 2012. Because nurses working in neonatal intensive care units from various provinces of Turkey attended these specified courses, we believed that this sampling method would reflect a more objective assessment. No selection of specific or randomized participants was conducted in this study. A total of nurses attending the courses at the specified dates and who agreed to participate in the study were included in the analysis. Data were collected through a questionnaire that we developed in accordance with current literature on nursing ethics $(2-4,8,9)$. The questionnaire consisted of two parts and 46 items. In first part, six questions determining demographic information (e.g. age, gender, marital status, period of work) were located. In second part, 40 items that determinate the ethical codes such as autonomy, beneficence, nonmaleficence, justice that nurses have to know and to do were located. These items were developed considering the research questions results of qualitative research, and evaluated taking into account the participants' statements. Four experts evaluated them for eligibility. Items' answers were never or always form. To gather data from the specified course, we obtained ethics board permission from the Faculty of Medicine Board of Ethics at Istanbul University. Furthermore, before the data collection, all participants were informed of the study procedure and their informed consent was obtained. The obtained data were analyzed on a computer using relevant statistical analyses (percentages, means).

\section{Results}

A total of 140 nurses participated in the study. Their average age was $29.9 \pm 5.55$ years (range: 19-42) and only four $(2.9 \%)$ were men. Half of nurses were single $(50 \%)$ and had an undergraduate degree (52.9\%). The average work experience was $8.76 \pm 6.54$ years (range: $1-24$ ). The percentages of nurses who paid attention or had some knowledge of the studied ethical issues while working are shown in Table 1. 
Turkmen AS et al.

\begin{tabular}{|c|c|c|c|}
\hline Ethical Principles & Ethical Approaches & Never & Always \\
\hline Autonomy-Respect for Persons & As human life needs to be protected, I reflect this to my practice & $0(0)$ & $140(100.0)$ \\
\hline Autonomy-Respect for Persons & $\begin{array}{l}\text { I attempt to provide service by taking the belief, values, and needs of } \\
\text { the individual into consideration }\end{array}$ & $8(5.7)$ & $132(94.3)$ \\
\hline Nonmaleficence & $\begin{array}{l}\text { I make efforts so that the individual does not experience maleficence } \\
\text { due to medical applications or clinical research }\end{array}$ & $8(5.7)$ & $132(94.3)$ \\
\hline Nonmaleficence & I attempt to provide nursing care with holistic approach & $4(2.9)$ & $136(97.1)$ \\
\hline Justice and equality & $\begin{array}{l}\text { I do not discriminate between individuals in my practices (race, lan- } \\
\text { guage, religion, political view etc.) }\end{array}$ & $12(8.5)$ & $128(91.5)$ \\
\hline Confidentiality & $\begin{array}{l}\text { I notify the mistakes of the team member that I work with to the } \\
\text { supervisor }\end{array}$ & $88(62.9)$ & $52(37.1)$ \\
\hline
\end{tabular}

a Data are presented as No. (\%).

Table 2. Distribution of Nurses According to Matters They Pay Attention to During Care ${ }^{\text {a }}$

\begin{tabular}{|c|c|c|c|}
\hline Ethical Principles & Ethical Approaches & Never & Always \\
\hline Nonmaleficence & I attempt to ensure the safety of the individual during care & $2(1.4)$ & $138(98.6)$ \\
\hline Autonomy-Respect for Persons & I attempt to respect autonomy during care & $4(2.9)$ & $136(97.1)$ \\
\hline Autonomy-Respect for Persons & I share my personal knowledge with patients & $120(85.7)$ & $20(14.3)$ \\
\hline Nonmaleficence & $\begin{array}{l}\text { I attempt to prevent individuals from encountering maleficence } \\
\text { during care due to lack of attention, lack of experience, and negli- } \\
\text { gence }\end{array}$ & $4(2.9)$ & $136(97.1)$ \\
\hline Nonmaleficence/ Beneficence & $\begin{array}{l}\text { I know the risks that may appear during care practices and attempt } \\
\text { to take measures }\end{array}$ & $8(5.7)$ & $132(94.3)$ \\
\hline Justice and equality & I prioritize patients that are related or acquainted with me & $118(84.3)$ & $22(15.7)$ \\
\hline Justice and equality & $\begin{array}{l}\text { I evaluate patients being disrespectful to nurses in care and treat- } \\
\text { ment after other patients }\end{array}$ & $126(90.0)$ & $14(10.0)$ \\
\hline Beneficence & When providing service, I can look out for my personal interest & $134(95.7)$ & $6(4.3)$ \\
\hline Protection of Privacy & $\begin{array}{l}\text { I try to protect the physical, psychological, and social privacy of the } \\
\text { individual I am serving }\end{array}$ & $6(4.3)$ & $134(95.7)$ \\
\hline
\end{tabular}

a Data are presented as No.(\%).

All of the nurses stated that human life must be protected, and thus they integrated this into their practice. Nearly all participants stated that they attempted to provide nursing care with holistic approach; that they attempted to prevent maleficence from affecting their patients during medical practice or research; that they provided service according to the beliefs, values, and needs of individual patients; and that they did not discriminate between patients in their practices. Around $84.3 \%$ of nurses stated that they did not accept the patient as problem free if she or he had no physical/psychological complaints, while 77.4\% stated that they devoted time to personal affairs when they had spare time at the hospital. More than half of nurses stated that they attempted to solve problems with workers in the work environment using their own methods, without notifying their superiors. When we examined the distribution in whether nurses reported the faults of their team members to superiors, we found that $37.1 \%$ notified their superiors and $62.9 \%$ did not (Table 1 ).
Nearly all nurses stated that during care they attempted to ensure the safety of the individual, respect their autonomy, prevent them from experiencing maleficence, and take measures against possible risks. Furthermore, 84.3\% of the nurses stated that they did not prioritize relatives or acquaintances, $90.0 \%$ did not delay the care of disrespectful patients, $85.7 \%$ did not share their personal information with patients, and $95.7 \%$ did not look out for their own personal interests. A large proportion of nurses stated that during care they were careful to protect patient privacy (Table 2).

A majority of nurses stated that they attempted to inform the patient regarding their care in a correct, adequate, and comprehensible manner. About three-quarters of the participants attempted to inform persons other than the patient that needed to be informed about the provided care. Finally, most did not share patient information with their friends as long as there was no medical justification (Table 3). 
Turkmen AS et al.

\begin{tabular}{|c|c|c|c|}
\hline Ethical Principles & Ethical Approaches & Never & Always \\
\hline Autonomy-Respect for Persons & $\begin{array}{c}\text { I try to inform the patient regarding care in a correct, adequate, } \\
\text { and comprehensible manner }\end{array}$ & $10(7.1)$ & $130(92.9)$ \\
\hline Autonomy-Respect for Persons & $\begin{array}{l}\text { I try to inform persons that need to be informed other than the } \\
\text { patient }\end{array}$ & $34(24.3)$ & $106(75.7)$ \\
\hline Autonomy-Respect for Persons & I leave the decision to the individual regarding care & $94(67.1)$ & $46(32.9)$ \\
\hline Autonomy-Respect for Persons & If the patient is refusing treatment, I respect this & $90(64.3)$ & $50(35.7)$ \\
\hline Protection of Privacy & $\begin{array}{l}\text { I share medical practices performed on the patient with health } \\
\text { personnel outside of the institution }\end{array}$ & $128(91.4)$ & $12(8.6)$ \\
\hline Autonomy-Respect for Persons & $\begin{array}{l}\text { I tell the bad outcomes in the health condition of the patient to } \\
\text { the patient. }\end{array}$ & $110(78.6)$ & $30(21.4)$ \\
\hline Protection of Privacy & $\begin{array}{l}\text { I share information on the health condition of patients with their } \\
\text { family and relatives }\end{array}$ & $84(60.0)$ & $56(40.0)$ \\
\hline Protection of Privacy & $\begin{array}{l}\text { I try to share the personal information of the patient with my col- } \\
\text { leagues in the ward even if there are no legal justifications }\end{array}$ & $128(91.4)$ & $12(8.6)$ \\
\hline
\end{tabular}

a Data are presented as No. (\%).

Table 4. Distribution of Nurses According to Their Status of Obtaining Consent During Practices a

\begin{tabular}{|c|c|c|c|}
\hline Ethical Principles & Ethical Approaches & Never & Always \\
\hline Autonomy-Respect for Persons & $\begin{array}{l}\text { I obtain verbal/written consent in nursing practices oriented at } \\
\text { the bodily integrity of the individual }\end{array}$ & $28(20.0)$ & $112(80.0)$ \\
\hline Autonomy-Respect for Persons & $\begin{array}{l}\text { I obtain consent from the lawful heir in practices oriented at indi- } \\
\text { viduals that are incompetent in decision making }\end{array}$ & $22(15.7)$ & $118(84.3)$ \\
\hline Autonomy-Respect for Persons & $\begin{array}{l}\text { In emergencies, I implement the necessary nursing care without } \\
\text { obtaining consent for the purpose of protecting the life of the } \\
\text { individual }\end{array}$ & $26(18.6)$ & $114(81.4)$ \\
\hline Autonomy-Respect for Persons & $\begin{array}{l}\text { In an emergency drug application I go through with the practice } \\
\text { even if there is no written request form }\end{array}$ & $58(41.4)$ & $82(58.6)$ \\
\hline Nonmaleficence/ Beneficence & $\begin{array}{l}\text { I do not practice if I have suspicions regarding medical instruc- } \\
\text { tions }\end{array}$ & $36(25.7)$ & $104(74.3)$ \\
\hline Nonmaleficence/Beneficence & $\begin{array}{l}\text { I assume responsibility for the patient, which I have provided } \\
\text { incorrect care or practices }\end{array}$ & $10(7.1)$ & $130(92.9)$ \\
\hline
\end{tabular}

a Data are presented as No.(\%).

When nurses' opinions on obtaining consent from patients during practice were examined, a large majority stated that they obtained verbal/written consent for procedures, oriented at the integrity of the patient or obtained consent from their lawful guardian if they were unable to obtain it from the patient. Furthermore, in emergencies, they did not obtain consent to provide necessary care for protecting patients' lives (81.4\%). About threequarters of nurses that had suspicions on the accuracy of medical instructions stated that they did not act on those instructions, while $12.8 \%$ stated that they did act on them. Furthermore, $82.8 \%$ stated that they assumed responsibility for errors occurring during practice (Table 4 ).

Exactly $64.3 \%$ of nurses reported having heard of nursing ethical codes. The sources of information for these nurses were nursing education (60.0\%), in-service training (28.9\%), periodical/ book/ friends (8.8\%), and hospital management $(2.2 \%)$. Of the nurses who knew about ethical codes, 93.3\% stated that they had heard of the principle of nonmaleficence/beneficence, $93.3 \%$ of the principle of autonomy/ respect for individuals, $95.6 \%$ of the principle of the protection of privacy, and $97.8 \%$ of the principle of justice and equality. Regarding nurses' actual utilization of ethical codes in the field, more than half of nurses $(52.2 \%)$ stated that they utilized all of the ethical codes, $54.7 \%$ stated that they utilized some of them, and $2.2 \%$ stated that they never utilized them. Many (72.3\%) nurses stated that they had seen no written materials on these ethical codes in their workplace. Of nurses who had heard of the ethical codes, $87.2 \%$ stated that they had attended an ethics course. All of the nurses stated that ethical codes should be known, 52.9\% stated that ethical codes should be known because the nurses themselves did not know them, 35.7\% stated that nurses should know these codes in order to be able to provide ethical care, and $11.4 \%$ stated that the codes should be known for work- 
er safety Nearly all of the nurses (95.7\%) stated that they would want information on ethical codes.

\section{Discussion}

In studies conducted on the information and applications of pediatric nurses on ethical codes, the majority of nurses were found to comply with ethical guidelines. Ethical practices have vital importance in the field of health) $(3,4,8,13-16)$. All of the nurses participating in the study stated that they reflected this in their practice, because human life must be protected. When the information and applications of nurses were assessed according to the principle of nonmaleficence, which is the foundation of nursing practice, we observed that nearly all of them complied with the principle of non-maleficence $(4,6,7$, $10-12,15)$. For example, $94.3 \%$ of nurses stated that they attempted to prevent the individual from encountering maleficence from medical practice or clinic research. In the same manner, a majority of nurses (97.1\%) stated that they attempted to prevent patients from experiencing maleficence due to negligence experience. One of the most important factors influencing patients' experiences of maleficence during care is that their nurses are unaware of the risks that may occur. A majority of nurses participating in the study (94\%) stated that they knew of the risks that may arise during care and took measures to prevent them from occurring or having an effect on patients. Another means of preventing patients from experiencing maleficence is not performing procedures that the nurses have reason to doubt the quality or correctness of. Thus, nurses must be aware that they do not necessarily need to perform treatment practices that have doubtful efficacy or correctness $(15,17)$. A proportion of $74.3 \%$ of nurses in our study stated that they did not follow any instructions that they doubted and 25.7\% stated that they would perform the medical application even if they knew it would cause maleficence for the patient. Medical procedures require responsibility; it is necessary for nurses to accept the possible outcomes of all procedures performed $(1,3,4,15)$. Nearly all of the nurses in this study (92.9\%) stated that they assumed responsibility for the patient's outcome when they performed incorrect care or treatment. The principle of autonomy/ respect for individuals suggests that each individual must make decisions about his or her own health. Thus, the service provided to each patient must be in line with his or her needs, without discrimination. However, in some cases, patients may be unable to make decisions on their own behalf. One of these cases would be a medical emergency, where it may be necessary for the nurse to make a decision on behalf of the patient (11). In this study, $81.4 \%$ of nurses stated that they applied necessary nursing care in emergencies without obtaining the consent of the patient in order to protect the patient's life, while $58.6 \%$ stated that they performed emergency medication applications even when they had no written request forms. Another instance where patients would be unable to make decisions regarding their own health would be when they are not old enough to be capable of making good decisions. In such a case, consent must be obtained from patients' guardians. In this study, the majority of nurses (84.3\%) stated that they obtained consent from legal guardians for procedures oriented at individuals that were not competent in making decisions. Health care is aimed at the recovery of patients' health. The consent of the patient is very important in any decision being made about health care $(1,4,15,16)$. In this study, more than half of the nurses stated that they would not leave the decision regarding care to the patient (67.1\%), and if the patient refused care, they would not respect this (64.3\%). This suggests that many nurses do not pay attention to patients' thoughts about their own health. Before any intervention can be applied to patients, it is necessary to obtain from them verbal or written consent $(3,13-15)$. In this study, $80.0 \%$ of nurses stated that they typically received verbal or written consent and $20 \%$ stated that they typically did not. One common unethical act is the sharing of patient information (14). In the present study, nearly all of the nurses (91.4\%) stated that they did not share the personal information of patients with their friends in the ward or health personnel outside of the institution without medical justification, and 60\% stated that they did not share this with family or relatives. Furthermore, a controversial issue is whether nurses should inform patients about the negative outcomes of their health condition. We found that around $78.6 \%$ of nurses stated that they did not tell patients about negative outcomes. Discrimination is defined as acting with a feeling of prejudice and protecting the rights of and providing more opportunities to one group of persons, while at the same time causing maleficence to another group (15). In this study, the majority of nurses (91.5\%) stated that they did not discriminate between individuals in their practice. Another case demonstrating discrimination would be that where patients exhibit disrespectful behavior towards nurses. We found that a majority of the nurses (90.0\%) stated that they did not postpone the care of disrespectful patients. This indicates that pediatric nurses do not appear to discriminate in general. Another act considered unethical is nepotism. Nepotism is acting in a way that ignores official obligations and prioritizes emotional or traditional engagements $(14,16)$. In this study, a majority of the nurses stated that they did not prioritize treating patients who are acquaintances or relatives, and $15.7 \%$ stated that they did prioritize. This finding indicates that only a few nurses act with nepotism in their practice. Although the rates were low, some nurses did engage in actions that went against the ethical codes. We think that this is because these nurses lacked sufficient knowledge about these ethical codes (35.7\%) and did not have access to written materials in their facility on ethical codes (72.3\%). Furthermore, it was observed that most nurses are open to and seek information on the ethical 
codes. We conclude that most nurses working in pediatric clinics act in compliance with ethical codes. However, only $64.3 \%$ of nurses knew of these codes. The best-known ethical code was the principle of justice and equality. Furthermore, while the rates were generally low, some nurses engaged in unethical practices such as patient discrimination and prioritizing acquaintances. We also found that the majority of nurses wanted to learn about ethical codes. For this reason, we recommended that nurses working in clinics and future nurses in training informed of the appropriate ethical behavior and codes.

\section{References}

1. Lachman VD. Practical use of the nursing Code of Ethics: part II. Medsurg Nurs. 2009;18(3):191-4.

2. Ersoy H, Yaytokgil M, Karakoyunlu AN, Topaloglu H, Sagnak L, Ozok HU. Single early instillation of mitomycin C and urinary alkalinization in low-risk non-muscle-invasive bladder cancer: a preliminary study. Drug Des Devel Ther. 2013;7:1-6.

3. Vanlaere L, Gastmans C. Ethics in nursing education: learning to reflect on care practices. Nurs Ethics. 2007;14(6):758-66.

4. Rosenkoetter MM, Milstead JA. A code of ethics for nurse educators: revised. Nurs Ethics. 2010;17(1):137-9.

5. American Nurses' Association. Code for Nurses. In: Beauchamp TL, Walters LR editors. Contemporary Issues in Bioethics.: Wadsworth Publishing Comp; 1989. pp. 312-6.
6. Cobanoglu N. Pure and Applied Medical Ethics.Ankara: Plato Publisher; 2009.

7. Maxcy RL. Public Health\& Preventive Medicine. 14 ed: Appleton \&Lange; 1998.

8. Kadioglu F, Kadioglu S. The Process of Ethical Decision Making in Clinical Practice. In: Demirhan AE, Oguz Y, Elcioglu O, Dogan H editors. Clinical Ethics.. Istanbul: Nobel Medicine Publisher; 2001. pp. 44-63.

9. Silva MC. Ethical Decision Making in Nursing Administration.: Appleton \& Lange; 1990.

10. Irgil E. Public Health and Ethics. In: Demirhan AE, Oguz Y, Elcioglu O, Dogan H editors. Clinical Ethics.. Istanbul: Spectrum Offset; 2001. pp. 295-304.

11. Eren N, Kalaca S. Medical Ethics. In: Guler C, Akın, L. editors. Public Health Basics.. Ankara: Hacettepe University Hospitals Publications; 2006. pp. 1190-9.

12. Iskit AB. Ethics Committees Formation, Development and Functions. Hacettepe Med J. 2005;36:129-34

13. Lachman VD. Practical use of the nursing code of ethics: part I. Medsurg Nurs. 2009;18(1):55-7.

14. Heymans R, van der Arend A, Gastmans C. Dutch nurses' views on codes of ethics. Nurs Ethics. 2007;14(2):156-70.

15. Verpeet E, Dierckx de Casterle B, Lemiengre J, Gastmans C. Belgian nurses' views on codes of ethics: development, dissemination, implementation. Nurs Ethics. 2006;13(5):531-45.

16. Numminen $O$, van der Arend A, Leino-Kilpi H. Nurse educators' and nursing students' perspectives on teaching codes of ethics. Nurs Ethics. 2009;16(1):69-82.

17. Gorgulu RS, Dinc L. Ethics in Turkish nursing education programs. Nurs Ethics. 2007;14(6):741-52. 